Journal of Universal Language 15-2

September 2014, 115-146

\title{
An Early 20th Century Korean Phonetic Alphabet
}

\author{
John Stonham \& Hyehyun Lee \\ Pukyong National University, Korea
}

\begin{abstract}
In this paper, we examine early efforts in English language education in Korea, focusing on a student's glossary of Chinese characters that contains Mandarin Chinese, English, and Japanese glosses of the meanings of each character. This book, the Ahak Pyeon, employs a modified version of the Korean Hangul writing system in order to phonetically render the English words, thereby facilitating the acquisition of English pronunciation for Korean learners. We examine the system proposed in this work in detail, noting issues of phonetic accuracy and clarity and assess it with
\end{abstract}

\footnotetext{
* We would like to thank Eun-Sook Kim for commenting on numerous versions of this paper. Our thanks also to the anonymous reviewers and the managing editor for their many useful comments on our submission.

John Stonham

English Language and Literature, Pukyong National University, Busan, Korea Phone: +82516295385; Email: stonham@pknu.ac.kr

Hyehyun Lee

English Language and Literature, Pukyong National University, Busan, Korea Phone: +82516295385; Email: hyehyun31@daum.net
}

Received June 23, 2014; Revised August 28, 2014; Accepted September 11, 2014. 
respect to its suitability as a linguistically-sophisticated phonetic transcription system suitable for the representation of English teaching. In this paper we discuss the principles employed in the Ahak Pyeon to render a reasonably accurate phonetic characterization of the pronunciation of the English words included in the book as well as a discussion of the challenges faced by the developer of the system. We discuss this work in terms of the general adaptability of the original Hangul writing system, the creativity of the revised system, and the potential of this system for developing phonemic awareness among Korean learners of English.

Keywords: English education, writing systems, phonetic transcription, Ji Seok-Yeong, Hangul

\section{Introduction}

Prior to the beginning of the 20th century there was virtually no use or even knowledge of English in Korea, with the possible exception of some early missionary work in the late 19th century. Early native efforts at English language education were limited and often undocumented.

In this paper, we examine one of the earliest of these efforts, a student's glossary of Chinese characters that contains glosses of the meanings of each character in Mandarin Chinese, Japanese, and, most importantly for this study, English transcriptions in a novel and, we will maintain, linguistically-sophisticated phonetic rendering. The book is entitled the Ahak Pyeon (henceforth AP), and was published in the first decade of the twentieth century under the direction of a Korean medical doctor and educator, Ji Seok-Yeong (1855-1935, henceforth JSY). Our view is that this work paved the way for later research and application in English language teaching, setting a standard in terms of the degree of linguistic sophistication it provided in the field of education at the 
time. We furthermore maintain that his contribution has not been fully appreciated in the field due to a lack of understanding of its sophistication and difficulty in terms of accessibility/availability of the original work.

In view of the fact that JSY's AP is written in Korean, the international community has, for the most part, been precluded from accessing it, resulting in very little previous research on it outside of Korea. Han (2009) has discussed the East Asian connection in the AP and Lee (2009) compares the Chinese characters in the AP with those of the Jeonjamun and the Jeongmongyu-eo. Han $(2007,2010)$ examine the representation of foreign words in various media, while Shin (2000) studies the use and nature of the Korean writing system in the early 20th century. Very little of this bears directly on the use of Hangul as a transcription system for the representation of English. Given what we will discuss concerning the AP in this paper, it is surprising that more scholars have not expressed any interest in this aspect of the work of JSY, which is contemporary with the development of the International Phonetic Alphabet (IPA).

In what follows, we will first present what we know about the author and other contributors to the AP, followed by a brief look at the format of the book, then discuss its layout and provide a sample entry to illustrate its structure and organization. We will then examine the linguistic features of the English entries, focusing on the innovative use of an extended Hangul alphabet in order to render features of English that are not easily represented in the standard Hangul alphabet.

Based on this analysis, we suggest that this transcription system demonstrates a high degree of linguistic sophistication and a good understanding of phonetics, in addition to a sound knowledge of the phonetic capacity and extensibility of the Hangul writing system. 


\section{JSY and the Ahak Pyeon}

The attribution of authorship of the AP is somewhat confused in the literature. Jeong Yag-yong (henceforth JYY), the famous early 19th century Korean educator, also known by the pen-name Dasan, is often regarded as the author of the AP, most probably due to his earlier work, the Myongmul Sohak (Jeong 1805, henceforth MMSH), upon which the AP is clearly based and also due to the mention of his name made in the introduction to the AP. This reference to JYY is an acknowledgement of his contributions to the reorganization of the Chinese characters in an order more accessible to Korean learners than an accurate description of his involvement in the later work. JYY had been dead for over 70 years when the AP was published. Hence, the relationship between his work and the AP is mainly in this order of presentation of the Chinese characters, an innovation in the adaptation of the Chinese Thousand Character Classic to Korean learners.

From the introduction to the AP and other bibliographic sources, it appears that JSY was the principal author of the 1908 version of the AP. There is scant information in the literature regarding JSY, but it is generally known that he was a medical doctor who introduced vaccines to Korea from Japan and that he founded the first medical school in Korea. His study of vaccines most probably convinced him of the importance of Western medicine and prompted his interest in Western scholarship and English language education as a tool to access knowledge of medical advances outside of Korea.

JSY was a member of the progressive and Western-leaning Independence Association and was involved in a number of activities concerning the Korean language. He was familiar with King Sejong's work on the Hunmin Jeongeum, the seminal document introducing the Korean Hangul writing system, and 
argued that many other scholars were not familiar enough with the system of the Hangul, even though it offered an excellent means to representing new sounds to facilitate learning. He argued that Hangul should be reformed to facilitate its learning by the people and developed improved methods of using Hangul to represent Chinese characters and sounds, as demonstrated in the AP. The following quote from Lee \& Ramsey (2011: 289) demonstrates the importance of JSY's contributions to Korean language modernization.

In 1905, the activist Chi Sŏgyŏng [= JSY] put forward a public appeal for the development of "new standards" of spelling and usage (新訂國文). This document quickly attracted enough public attention to affect government policy, the first to do so, and in 1907 the newly established Institute for the Study of Korean Writing (Kungmun Yŏn'guso) took up Chi's proposal and began serious work on the project.

JSY's contributions to English education are generally less well known, but the AP attests to his interest in language education issues and in the teaching of English language.

In the introduction to the AP Jeon Yong-gyu is mentioned as a contributor to the work, due to his knowledge of both English and Japanese. He was a co-worker of JSY at the Severance hospital, the oldest western-style hospital in Korea. We assume that Jeon Yong-gyu was an important source of data on the pronunciation of both English and Japanese, as noted in the preface to the AP.

An additional issue concerning the AP is the actual date of publication, since there appear to be two radically different versions of the text with the same title published several years apart. One version contains Mandarin Chinese, Japanese, and English pronunciations, whereas the other has neither English nor Mandarin Chinese. The former version is dated on the cover of the 
book as "Yunghi 1st Year, 9th month," i.e., March 1908, while the other is dated "Yunghi 4th Year, 5th month," December 1910. If these dates are correct, then the later version appeared several months after the signing of the Japan-Korea Annexation Treaty (signed August 22, 1910) and removed both Modern Chinese and English words and pronunciations from the entries.

We should note here that the versions of the texts employed for this study come from two main sources: i) a Japanese volume, Jigakuhen. Nichigo Ruikai. Kango Shoho (1970) containing several works published in the same era (AP 1908); and ii) the Korean National Library digital database (AP 1910).

There is reason to believe that JSY may have only been directly involved with the earlier, 1908 version and the actual author of the later, 1910 version is unclear. One clue to this issue of authorship has to do with the use of a more conservative version of the Hangul writing system in the later work. Since JSY was known to be progressive in his attitude to the Korean writing system, as attested in the above quote from Lee \& Ramsey (2011) and supported by his own modifications to the pronunciations in the 1908 version, it is unlikely that he would have reverted to an older style in the representation of Korean pronunciation for a later edition of the AP. Examples of this type of discrepancy include the use of arae $a$ to render [æ], and of $\bar{\delta}$. / /hai/1 to render 해 $/$ hæ/, the latter exemplified by the differences shown in figures 1 and 2 below. In addition to this consistent difference in the representation of vowels, only the 1908 version indicates the presence of vowel length (by a raised quote / '/), which is still an important phonological feature of Korean at the time. Since it would seem unlikely that JSY would revert to an older form of the vowel representation and at the same time remove important

1 In this paper, square brackets, [ ], are employed to indicate phonetic transcription and slashes, / /, are used to transliterate the Hangul symbols for readers unfamiliar with the Hangul writing system. 
information regarding vowel length that was found in the 1908 version, it seems more probable that the 1910 version of the AP was authored by another person who was not fully familiar with JSY's system.

We will focus here on the earlier, 1908 version, which contains the English entries with their phonetic transcriptions (Figure 1), in addition to other details. Figure 2 provides a sample entry from the later 1910 edition for comparison.

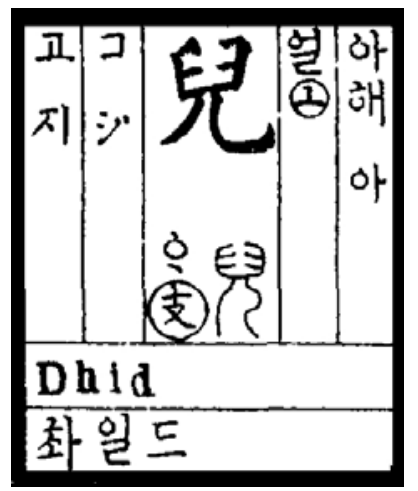

Figure 1. 1908 Ahak Pyeon

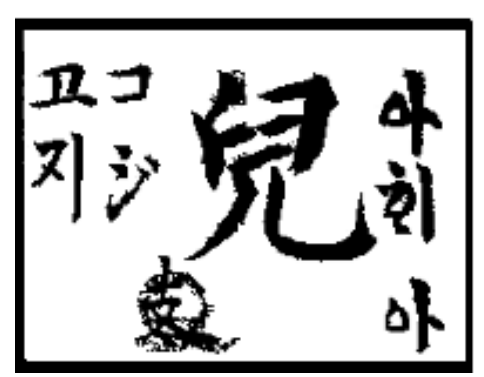

Figure 2. 1910 Ahak Pyeon

\section{Format of the Ahak Pyeon}

The AP is basically a quadrilingual glossary of Chinese characters for the use of students. The version we examine here reflects the Korean orthographic conventions and pronunciations of that time. Entries, which henceforth will be referred to by page number and side within brackets, e.g., [1a] to indicate the recto of the first page, consist of a number of different types of information, organized in the fashion presented in Figure 3:

The explanation of the various parts of each entry is as follows. 


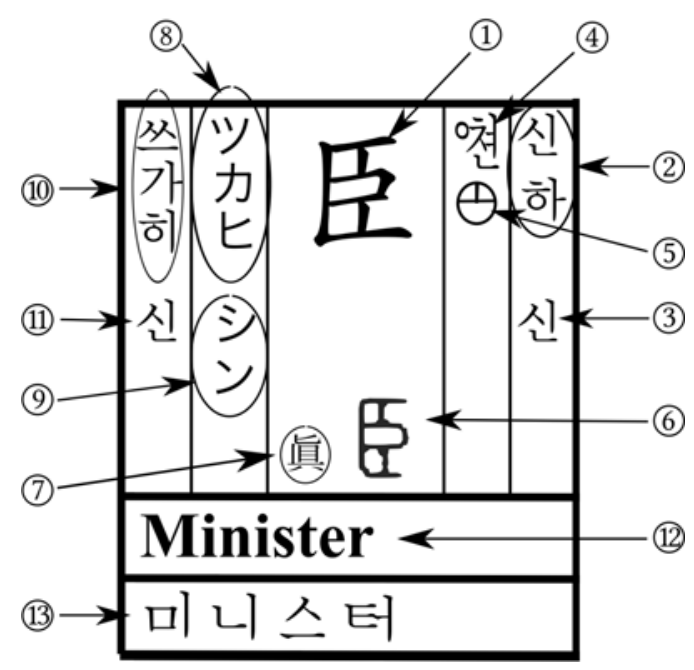

Figure 3. Entry from AP 1908 [1a]

(1) is the main entry, a Chinese character with the meaning 'minister of state,' the sixth entry in the AP and in JYY's textbook. (2) provides the Korean definition of this character; usually this will be the native Korean gloss of the word, e.g., 天 is defined as 하날 /hanal/, the version employed at this time. Where there is no appropriate native Korean word for the Chinese character, the usual Sino-Korean form of the word is used, shinha in the case of Figure 3. (3) is the Sino-Korean pronunciation of the Chinese character. (4) gives the Standard Mandarin Chinese pronunciation of the character, employing Hangul to approximate the phonetic transcription of the Mandarin [ $\left.\mathrm{t} \int 2 \mathrm{on}\right]$. (5) provides the relevant Mandarin Chinese tone of the character, in Figure 3, the second or rising tone. (6) gives earlier/archaic forms of the character and (7) provides a rhyming character, in this case 唇 [dzin], based on Sino-Korean pronunciation, not Mandarin, which would be [dzən]. (8) provides the native Japanese (Kun-yomi) reading of the Chinese character in katakana and (9) gives the 
Sino-Japanese version (On-yomi), also in katakana. (10) and (11) provide the phonetic transcription of these two Japanese forms, respectively, using a modified Hangul system to closely render the Japanese pronunciations. (12) provides the English orthographic form of the meaning of the Chinese character, glossed in a simple one- or two-word phrase. (13), which will be our main point of focus in this paper, provides a phonetic transcription of this English word/phrase, employing the same modified Hangul system as used for the Mandarin Chinese and the Japanese. We will discuss the various modifications to the Hangul system as employed for transcribing English words in section 5.

Clearly, the AP makes its own significant contribution to education through the addition of both Japanese and English orthographic representations of the Chinese characters, as well as phonetic transcriptions in Mandarin Chinese, Japanese, and English. In addition to this, much of the Korean data was modernized from the early 19th century pronunciations provided by JYY.

We will, in the remainder of this paper, focus on the English forms and the way they are represented in the AP. We will examine the accuracy of the phonetic representations provided for English words and the novel modifications to the Hangul writing system that were employed in order to render the English pronunciations. Following the examination of the system, we will discuss the important contribution that JSY made to English education in the AP.

\section{On the "System" in JSY'S Transcriptions}

Before continuing we should note that the system of representation that we are discussing in this paper is not a transliteration scheme, used for rendering foreign names in 
standard written Korean, as may be found in newspapers or magazines, but rather a phonetic transcription of the pronunciation of a foreign word which is capable of accurately rendering a close approximation of the original word. For example, compare the typical rendering of the word Bavaria in current standard Korean, 바바리아/paparia/, versus the phonetic rendering of the same place name in Mackenzie (1895), 사아리아 /p'avaria/. As is readily evident from the IPA rendering of the two forms, the former employs only the standard Hangul symbols, which limits the phonetic accuracy but economizes on the typesetting, whereas the latter provides a far more accurate pronunciation at the expense of orthographic complexity. It is the latter form of representation that interests us here.

The former type of adaptation may be referred to as hangulization, by analogy with the term romanization for the use of the Roman script in representing foreign words in English, such as kimchee, Seoul, Hyundai, etc. Such forms of representation are attempts at providing a rough approximation of a foreign word in a form that fits within the borrowing language's own phonetic system. The system employed in the AP is a true phonetic transcription system intended to aid learners in developing an accurate pronunciation of foreign words as pronounced in the foreign language, not simply the adaptation of foreign words to Korean pronunciation. This is an important distinction that is often confused in the study of representations of foreign words.

JSY outlines his system for transcribing the Chinese, Japanese, and English versions of the characters in the AP in the introduction to the book. He provides charts and tables, in addition to explanations, in order to make the transcription system as clear as possible for the reader.

The Chinese transcription, as in (4//5) in Figure 3 above, provides a current, Mandarin pronunciation of the Chinese character, 臣 chén [t én], including an indication of the proper tone, using the same transcription system as used for English and 
Japanese. Choi (2006) has discussed the nature of the Chinese transcriptions in the AP in detail, so we will not pursue this other than to provide a few examples of special usage in Table 1.

Table 1. Examples of Chinese Transcription

\begin{tabular}{|c|c|c|c|c|c|c|c|c|}
\hline & Pron. & Symbol & Character & Meaning & Mandarin & $\begin{array}{c}\text { Native } \\
\text { Korean }\end{array}$ & $\begin{array}{c}\text { Sino- } \\
\text { Korean }\end{array}$ & $\begin{array}{c}\text { Ref. } \\
\text { No. }\end{array}$ \\
\hline 1 & Z & $\triangle$ & 日 & sun, day & $\Delta l$ & $\begin{array}{c}\text { 날 } \\
/ \text { nal/ }\end{array}$ & $\begin{array}{c}\text { 일 } \\
/ \mathrm{il} /\end{array}$ & {$[6 \mathrm{a}]$} \\
\hline 2 & $\mathrm{f}$ & 붕 & 父 & father & 부 & $\begin{array}{c}\text { 아비 } \\
/ \mathrm{abi} /\end{array}$ & $\begin{array}{c}\text { 부 } \\
/ \mathrm{pu} /\end{array}$ & {$[1 \mathrm{a}]$} \\
\hline 3 & diao & 돠 & 貂 & sable & 돠 & $\begin{array}{c}\text { 돈피 } \\
/ \text { donpi/ }\end{array}$ & $\begin{array}{c}\text { 초 } \\
/ \mathrm{cho} /\end{array}$ & {$[17 \mathrm{a}]$} \\
\hline
\end{tabular}

The first row illustrates the use of the Middle Korean pansios, $\Delta$, to represent the voiced retroflex fricative, [z], in modern Mandarin, reflecting a similar use in Middle Korean (Stonham \& Kim 2010). The second row illustrates the similar use of Middle

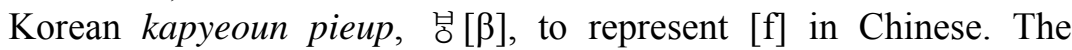
third example, 돠 $/ \mathrm{twja} /$, merits brief examination. In order to pronounce this form correctly, one must violate the natural expected reading order of the elements in the Korean syllable, reading first $ᄃ / \mathrm{t} /$ then $k / \mathrm{ja} /$ and finally $\perp[\mathrm{w}]$, giving the correct Mandarin pronunciation diao, rather than the expected natural order of $ᄃ / \mathrm{t} /$ then $\perp / \mathrm{w} /$ and finally $k / \mathrm{ja} /$, which would render the very awkward pronunciation of $/ \mathrm{dwja} /$. This syllable is, in fact, unpronounceable in Korean, but compare this with the syllable 돠, for example, which is pronounced /twa/, i.e., ᄃ $\rightarrow \perp$ $\rightarrow$ F.2 This is a good example of the sophistication of JSY's system, which employs not only special symbols to represent

2 Found, for instance, in the Indian place name 크한돠 /kihandwa/, "Khandwa, Madhya Pradesh" or the contracted form for 도와주세요: 돠주세요 /towad3usejo : twad3usejo/ "Please help." 
foreign sounds, but also its own conventions for interpreting the transcriptions, including modifications to the reading order of syllables.

Similarly, Japanese is transcribed using the same, Hangul-based transcription system, as indicated in Figure 3, (10) for kun-yomi and (11) for on-yomi. Special features of the transcription system for Japanese include the use of Korean saisios for indicating Japanese consonant gemination (rendered in katakana by the sokuon) as in 닷도후/tatt'ohu/ for <タットフ> 'minister' [3b], as well as the use of Korean $\lambda+$ consonant to indicate the voicing of Japanese consonants (discussed in the introduction but not used in the main body of text), and the indication of the Japanese nasal / $\tilde{g} /$ (found in some pronunciations) by means of a preceding velar nasal $(0)$ followed by an onsetless syllable, as shown in 뎅아미 /tejami/ <广 ガミ>/teg̃ami/ 'letter' [24b].

Seong (2002) has examined the Japanese transcriptions and noted errors, but these are typically, like many of the English cases, errors of data familiarity, not of analysis. We refer the reader to Seong (ibid.) for a discussion of the Japanese representations in the AP.

As an example of the general, consistent application of this Hangul-based transcription system, we will briefly examine the marking of vowel length in the AP. Vowel length is indicated in the Korean, Japanese, and English transcriptions by the use of a raised accent mark $/$ ' / to the right of the affected syllable. In Korean, this indicates the traditional length distinction in forms such as 장'수/dzansu:/ 'general' and 장수/dzansu/ 'long life,' where the initial syllable of the former word exhibits greater weight than in the latter. ${ }^{3}$ In Japanese, length is a distinctive characteristic of the vowel system and is indicated in transcriptions such as 보' /po:/ for Japanese ボウ /bou/ (母 'mother' [1a]; also

3 This is still true in some dialect pronunciations although Modern Standard Korean no longer reflects this vowel length consistently. 
used to indicate the English word 'bow,' as in bow tie). For English, the length mark is used to indicate (i) the absence of [r] in non-rhotic pronunciation of forms such as 'officer' 오이써' /ofuis'J/ [2b], (ii) tense vowels such as [i:] in 티'춰 $/ \mathrm{t}^{\mathrm{h}} \mathrm{i}: \mathrm{t}^{\mathrm{h}} \mathrm{WJ} /$ 'teacher' [2a], (iii) diphthong length in 으렐네'트 /irelne:thi/ 'relate' [2a], and (iv) certain vowel modifications, such as 안'트 /a:

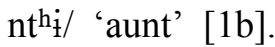

This consistent use of this diacritic, / ' /, across languages demonstrates the general applicability and extensibility of the system. It seems clear that JSY intended his system to be used as a universal phonetic alphabet for the recording of pronunciation in any language. We now move on to a more detailed examination of the use of JSY's system in the representation of English pronunciations.

\section{The Phonetic Rendering of English}

Transcribing the words of one language in a way that makes sense in another language involves many considerations. When the two languages employ very different orthographic systems, the problems are compounded. And when the sound inventories of the two languages are very different, even greater challenges arise. Note that this process is distinct from transliteration, which may simply assign a one-to-one mapping of the symbols of the source language to those of the target. These latter systems do not aim at phonetic accuracy, but require an in-depth knowledge of the sound systems of both languages as a starting point. A phonetic transcription system, on the other hand, assumes no such prior knowledge and aims to provide a means to acquire as accurate a pronunciation as possible for those who are not yet familiar with the target language.

As shown in Figure 3 above, the bottom of each entry in the 
AP has two lines dedicated to English. The first of these is an orthographic presentation of the English word or phrase considered to be closest to the meaning of the Chinese character. Given that there is often an uneven correspondence between the meanings of words in the two languages, the choice of this word is often infelicitous but may be said to give a rough approximation of meaning. For example, the Chinese character, 尖, is glossed in English as 'acuminous,' a rather uncommon word, when 'keen, sharp, acute' might have been more appropriate and the character 烈 is glossed as 'pickingbird' rather than the usual 'woodpecker.'

The second English-related line in the representation is the most germane to our study here. It provides a phonetic rendering of the English word, employing the Hangul alphabet in the modified form developed by JSY, in order to present a pronunciation that is as accurate as possible.

In what follows, we will discuss how JSY modified the Hangul alphabet in a variety of ways, sometimes adopting symbols from earlier, Middle Korean usage and sometimes creating his own versions of symbols, consistent with the Hangul system, in order to create a Korean phonetic alphabet for the transcription of foreign languages, including English.

We will proceed through the different phonetic categories of sounds, examining each in turn to see how they are represented in JSY's system, beginning with the nasal consonants.

\subsection{Nasal Consonants $[\mathrm{m}, \mathrm{n}, \mathrm{\eta}]$}

Nasal consonants, [m, n, y], are basically the same in English and Korean. For this reason, the English nasal consonants can be adequately rendered by the equivalent existing Hangul symbol in a straightforward, one-to-one fashion, as shown in (1). 


$\begin{array}{llll}\text { (1) mind 마인드 } & / \text { ma.inti } / & {[5 \mathrm{a}]} \\ \text { moon } & \text { 문 } & / \mathrm{mun} / & {[6 \mathrm{a}]} \\ \text { spring } & \text { 스푸링 } & / \mathrm{sip}^{\mathrm{h}} \mathrm{urij} / & {[8 \mathrm{a}]} \\ \text { palm 팜' } & / \mathrm{p}^{\mathrm{h}} \mathrm{a}: \mathrm{m} / & {[4 \mathrm{~b}]} \\ \text { nose 노쓰 } & / \text { nos'i }^{\prime} / & {[3 \mathrm{~b}]}\end{array}$

English nasal sounds pose little difficulty with respect to pronunciation. The only thing to note here is the case of English $<\mathfrak{y}>$ which is sometimes accompanied by a following velar segment 그, for instance. While the appearance of [9] is also known to occur in certain dialects of English, for instance, in Liverpool dialect, it is considered non-standard. Note that, in Standard English, there is a contrast word-internally between forms such as finger [fIngəx] versus singer [sinəx], but this contrast does not occur at the end of the word. Thus, we find tongue rendered as 텅그/tonki/ [4a] and wing as 윙그/winki/ [20b] but spring is accurately represented without the following 그, as in spring 스푸링 / $\operatorname{sip}^{\mathrm{h}} \mathrm{urin} /$ [8a] and awning 아운잉 /a.unin/ [23b]. The addition of 그 may be an analogical formation based on English words such as bank 방크 / $\mathrm{pank}^{\mathrm{h}} \mathrm{i} /[7 \mathrm{a}]$ or ink 잉크 $/ \mathrm{ink}^{\mathrm{h}}$ i/ [24b], where a final voiceless velar segment does, in fact, follow the $<$ ng $>$. Note that the final consonant symbol in these latter cases is the one employed to represent English $<\mathrm{k}>$, whereas the symbol used for tongue and other similar cases is used by JSY to represent English $<\mathrm{g}>$.

There is no systematic representation of syllabic nasals in JSY's system, many examples being rendered according to orthography, e.g., cotton 코톤 $/ \mathrm{k}^{\mathrm{h}} \mathrm{ot}^{\mathrm{h}} \mathrm{on} /[15 \mathrm{a}]$.

\subsection{Voiceless Stops $[p, t, k]$}

Initial voiceless stops, which appear in English words like people, teacher, and concubine, are represented using the Hangul symbols for Korean voiceless aspirated stops 프, E, ㄱ, much as 
they are in English loanwords today, e.g., party 파티 $/ \mathrm{p}^{\mathrm{h}} \mathrm{a} \mathrm{t}^{\mathrm{h}} \mathrm{i} /$, team 팀 $/ \mathrm{t}^{\mathrm{h}} \mathrm{im} /$, cocoa 코코아 $/ \mathrm{k}^{\mathrm{h}} \mathrm{ok}^{\mathrm{h}} \mathrm{oa} /$. This reflects the fact that in English such sounds are aspirated when they occur at the beginning of the word. Examples of such cases from the AP include those in (2).

(2)

\begin{tabular}{|c|c|c|c|}
\hline a. people & 피오필 & $/ \mathrm{p}^{\mathrm{h}_{\mathrm{i}} . \mathrm{op}^{\mathrm{h}} \mathrm{il} /}$ & {$[2 b]$} \\
\hline top & 톱푸 & $/ \mathrm{t}^{\mathrm{h}} \mathrm{opp}^{\mathrm{h}} \mathrm{u} /$ & {$[4 \mathrm{a}]$} \\
\hline kite & 카이트 & $/ \mathrm{k}^{\mathrm{h}} \mathrm{a} . \mathrm{it}^{\mathrm{h}} \mathrm{i}_{\mathrm{f}}$ & [16b] \\
\hline b. spring & 스푸링 & $/ \operatorname{sip}^{h} u \sin /$ & [8a] \\
\hline star & 스타아' & /sitha.a:/ & [6a] \\
\hline sky & 스카이 & /si. $\mathrm{k}^{\mathrm{h}} \mathrm{a} . \mathrm{i} /$ & [1a] \\
\hline
\end{tabular}

These symbols ensure that the English voiceless stops are correctly pronounced in initial position, i.e., with aspiration. However, it should be noted that the aspiration in English voiceless stops is typically suppressed when following [s], as in spot, stop, scot. This level of narrow phonetic distinction does not appear to be indicated in the AP, as in (2b), or in subsequent representations of English in Hangul up to the present. Word-final voiceless stops are invariably represented by the Hangul aspirated series, for example, stop 스톱푸 $/ \mathrm{sit}^{\mathrm{h}} \mathrm{opp} \mathrm{p}^{\mathrm{h}} \mathrm{u} /$ [55a], breast 수레스트 /puresit $\mathrm{t}_{\mathrm{i}} \mathrm{i} /$ [4a], smoke 스목크 $/$ simokk $^{\mathrm{h}} \mathrm{i} /$ [11a]. One interesting feature of this position is the occasional doubling of the final consonant (one plain followed by one aspirate) in the labial and velar series but not among the alveolars, which are never doubled in this context.

\subsection{Voiced Stops $[b, d, g]$}

Voiced stops in English, as found in the initial position of words such as book, doctor, guest or at the end of words like cab, bed, 
bag, are distinct from the voiceless stops and should therefore be represented distinctly. JSY renders this difference by using the Hangul sequence of $\lambda+$ consonant, which at that time was one way to represent the tense consonants of Korean, i.e., 뻐, $[\ulcorner, 77$. Phonetically, these consonants are unaspirated and pronounced with a certain amount of tension in the vocal tract. Thus we find Korean forms such as 상 /t'ay/, 'earth' [1a] now written 땅 /t'ay/ or 샴 /p'jam/ 'jaw' [4a] now written 뺨 /p'jam/ ('cheek'). The AP provides examples such as (3).
(3) back
사크
$/ \mathrm{pik}^{\mathrm{h}} \mathrm{i} /$
dragon
스랎건
/ticakkon/
[4b]
garlic
짤르크
$/ \mathrm{kal}_{\mathrm{rik}} \mathrm{h}$ /

The Korean tense consonants, 바, ㄷ, 77 , and so on are never used in the transcription of English final consonants.

\subsection{Liquids $[r, \mathbf{l}]$}

JSY introduces a special convention with regard to his representation of the difference between English [r] and [1]. Since Korean has only a single liquid consonant phoneme with two alternating phonetic realizations depending on position, only one symbol, ᄅ, is necessary for Korean words. However, English makes a clear distinction between the two liquids, e.g., royal versus lawyer. Word-medially, it is possible to achieve this distinction by the use of two occurrences of Hangul 르 in adjacent syllables to replicate the distinction in Korean, thus, solo versus sorrow may be represented as 솔로/solro/ versus 소로 /soro/. This solution is often employed in present-day renderings of English loanwords, but there is a problem in one particular domain: the beginning of the word. Since $ᄅ$ cannot be doubled initially, how does one distinguish between rock and lock? 
JSY's solution to this problem is to introduce a default vowel symbol, the Korean vowel -, into an initial syllable in combination with either a single or double occurrence of $ᄅ$ in the subsequent string of symbols. If it were a singleton, then the pronunciation would be English [ $\mathrm{I}$ ], as in rock 으록크 /írokk ${ }^{\mathrm{h}} \mathrm{i}$ / [7b], whereas if it were doubled, 르, an English [1] would be the result, as in lock, rendered as lock 을록크 /illokk ${ }^{\mathrm{h}} \mathrm{i} /$ [22b].

This represents a truly ingenious solution to the use of a single symbol to make two different distinctions. It shows a sophisticated understanding of phonetic/phonemic representation at roughly the same time that the International Phonetic Association was developing their phonetic alphabet. Note that the use of - as an epenthetic vowel is already well established by its use to break up syllable-initial clusters, as in scale 스케일 $/ \mathrm{sik}^{\mathrm{h}} \mathrm{e} . \mathrm{il} /$ [20b] and skin 스킨 $/ \mathrm{sik}^{\mathrm{h} i n} /[5 \mathrm{~b}]$.

It is worth remarking that English final r-sounds are not indicated in the transcription, but may be noted by the lengthening of the preceding vowel in JSY's system, e.g., star 스타아' /sith a.a:/ [6a], deer 시'아/ti.a/ [17a], etc. English final [1] appears as a single ᄅ, e.g., ball 솔 /pol/ [25a], call 콜' $/ \mathrm{k}^{\mathrm{h}} \mathrm{ol}: /$ [44b], etc. (more on length marking in section 5.8). No distinction is made between English clear and dark /1/ in the coda, both being rendered with the Hangul ᄅ.

\subsection{Fricatives}

Some of the most interesting modifications to the system appear in the representation of English fricatives. English possesses a much more complex system of fricative sounds than Korean, including labiodental /f, $\mathrm{v} /$, interdental $/ \theta$, б/, alveolar $/ \mathrm{s}, \mathrm{z} /$, alveopalatal $/ \int, 3 /$ and glottal $/ \mathrm{h} /$. The Modern Korean phonological system has only three fricatives, 入, 从, $\overline{0}$, which is insufficient to represent all the various places of articulation occurring in English fricatives. For this reason, it was necessary 
for JSY to introduce a number of modifications to his system of phonetic representation of English in order to accommodate the large range of fricative sounds. The common English word, father, illustrates this aptly, as shown in (4).

(4) father 으아어 /fi.aðว/ [1a]

Notice that this word possesses two fricatives, [f] and [ð], not found in Korean. Word-initially, it has [f], a voiceless labiodental fricative also found as the first sound in fox and funny and as the last sound in half and cough. In order to approximate this sound using the Hangul writing system, JSY co-opts an original Middle Korean symbol, 풍, used at that time to represent a voiceless bilabial fricative, $[\Phi]$, found in the Mandarin Chinese of the time. However, JSY restructures the symbol, placing the circle on the side rather than underneath, thus oㅍ. This modification may have been for typographic convenience, since the Middle Korean symbol was no longer employed, but both $O$ and 프 were readily available as independent symbols. Parallel to this modification of 풍, we find a similar modification of $\theta \dot{O}$ in the form 으, which is employed to represent English [v], as in vein, vat, etc. Examples of the latter in the AP include English river, represented as 으리어 /irivo/ [8a] and vessel 에샐 /vesæl/ [25a].

For the voiced interdental fricative, [ð], a sound occurring word-medially in cases such as father and mother, JSY employs a novel collocation, or, thereby extending the Middle Korean convention for using $O$ under consonant symbols to make 'light' (fricative) versions of those sounds. This principle was introduced in the Hunmin Jeong-eum in order to represent fricatives found in foreign languages like Chinese /f/, but was never used with $ᄌ$, since there was no need for it at that time. JSY applies the principle to create a symbol for English /ð/, recognizing both its fricative and voiced qualities and assigning it to an interdental 
place of articulation.

In like fashion, JSY creates o[ to represent English $/ \theta /$, represented in the English orthography as <th $>$, occurs in many words in word-intital, word-medial, and word-final positions as exemplified by thin, catheter, beneath, respectively. To the best of our knowledge, these symbols are entirely novel innovations of JSY, but they clearly demonstrate the genius of the originators of the Hangul system, who anticipated future needs and created a writing system which was open-ended enough to allow for such extensions in a simple and straightforward fashion.

With respect to the English alveolar fricatives, /s/ and $/ z /$, word-initial [s] is usually represented by Hangul 从ᄊ, e.g., 씨 / $/ \mathrm{s}^{\prime} \mathrm{i} /$ 'sea,' but by ᄉ when followed by a consonant, e.g., 스킬 /sik ${ }^{\mathrm{h} i 1 /}$ 'skill [39a].' It is more inconsistently represented by either Hangul 人 or 씨 in some cases, such as sit 시트 / $\operatorname{sit}^{\mathrm{h}} \mathrm{i} /$ [43b] but six 씩스 /s'iksi/ [61b]. [z] does not appear with any indication of voicing, thus ease or fuse are represented as 이'스/e:si/ [53b] and 익유쓰 /fuijus't/ [46a], respectively. Most instances of [z] employ 从. Orthographic $<_{\mathrm{Z}}>$ is treated in like fashion, for example 'gauze' 싸 우쓰 /ka.us'í/ [28b], 'lazy' 을 네이씨/ilnes'ít [60b], 'sneeze' 스네' 丛 /sines'ít [38a], etc.

The alveopalatal fricative [ [] is most commonly represented with labialization, as in (5a). This reflects the typical lip-rounding inherent in the English sound (Proctor, Shadle \& Iskarous 2006). English [3] is not marked for voicing and is thus not distinguished from $\left[\int\right]$, as illustrated in (5b).

$\begin{array}{llll}\text { (5) a. fish } & \text { 역쉬 } & / \mathrm{fi} \int \mathrm{i} / & {[20 \mathrm{a}]} \\ \text { sheep } & \text { 쉬이뿌 } & / \int \mathrm{i} . \mathrm{ipp}^{\mathrm{h}} \mathrm{u} / & {[17 \mathrm{~b}]} \\ \text { shrimp } & \text { 쉴림푸 } & / \int \text { wiripp }^{\mathrm{h}} \mathrm{u} / & {[18 \mathrm{~b}]}\end{array}$

b. liesure 을 네쒀 /ilnes'wo/ [53b] $[$ sic $=$ 'leisure'] 
Finally, English $/ \mathrm{h} /$ is represented uncontroversially by Hangul ㅎ, as in 'hat' 하트 / $\mathrm{hat}^{\mathrm{t}} \mathrm{i} /$ [29b] or 'hill' 힐 /hil/ [7b].

In summary, English fricatives are generally distinguished in JSY's system, with the exception of voiced alveolar and alveopalatal fricatives [z] and [3], which are merged with their voiceless counterparts. Curiously, both labiodental and interdental fricatives are distinguished for voicing.

\subsection{Affricates}

English affricates are represented in Hangul by their counterparts in Korean: $/ \mathrm{t} \int /$ by ㅊ, and $/ \mathrm{d} 3 /$ by $从$ X. Like the alveopalatal fricatives, the alveopalatal affricates are usually accompanied by an indication of lip-rounding which is inherent in the English sound (Proctor, Shadle \& Iskarous 2006). This is illustrated in the following examples.

(5)
a. teacher 티'춰 $/ \mathrm{t}^{\mathrm{h}} \mathrm{i}: \mathrm{t}^{\mathrm{h}} \mathrm{W} / \quad$ [2a] chair 췌아 $/ \mathrm{t} \int \mathrm{h}$./
child
촤일드 $\quad / \mathrm{t} \int^{\mathrm{h}} \mathrm{Wa}$.ilti/
[1a]
$\begin{array}{llll}\text { b. cabbage } & \text { 캅세에쥐 } & / \mathrm{k}^{\mathrm{h}} \text { app'e.ed3wi/ } & {[12 \mathrm{~b}]} \\ \text { junk } & \text { 쩡크 } & / \mathrm{d}_{3} 3 \mathrm{yk}^{\mathrm{h}} \mathrm{i} / & {[23 \mathrm{~b}]}\end{array}$

Interestingly, the voiced and voiceless alveopalatal affricates are differentiated by the use of $\bar{\lambda}\left[\mathrm{t} \int\right]$ and $大 ~[\mathrm{~d} 3]$, unlike their fricative counterparts discussed above.

\subsection{Vowels and Diphthongs}

Vowels are often more difficult to characterize accurately, and the English tendency to reduce vowels in unstressed syllables further complicates attempts to provide a consistent rendering of similar 
words. For instance, batten versus baton, relay versus rely, etc.

In JSY's system, most English vowels use the nearest equivalent Hangul symbol. Distinctions between [i] and [I] or [u] and [v] are not made by different vowel symbols, since this distinction is not contrastive in Korean. Occasionally, this tense/lax contrast is indicated by means of the Hangul length mark to be discussed below. The examples in (7) demonstrate the absence of the distinction.

\begin{tabular}{|c|c|c|c|}
\hline (7) beak & 비크 & $/ \mathrm{pik}^{\mathrm{h}} \dot{\mathrm{i}} /$ & {$[20 \mathrm{~b}]$} \\
\hline pit & 피트 & $/ \mathrm{p}^{\mathrm{h}_{\mathrm{i}} \mathrm{t}_{\mathrm{i}} / \mathrm{s}}$ & {$[7 \mathrm{~b}]$} \\
\hline root & 으루트 & /isuth ${ }^{\mathrm{i}} /$ & {$[14 b]$} \\
\hline book & 수크 & $/ p^{\prime} u^{h}{ }^{h} /$ & {$[24 \mathrm{~b}]$} \\
\hline
\end{tabular}

English diphthongs are represented, for the most part, as they are in current Korean transliteration, as a sequence of two heterosyllabic vowels as exemplified by (8).

\begin{tabular}{|c|c|c|}
\hline sky & 스카이 & $/ \mathrm{sik}^{\mathrm{h}} \mathrm{a} . \mathrm{i} /$ \\
\hline male & 메일 & /me.il/ \\
\hline boy & 소이 & /p'o.i/ \\
\hline bound & 새운드 & /p'a.unti/ \\
\hline bow & 송우 & /p'o.u/ \\
\hline
\end{tabular}

This results in an additional syllable in the representation, but there are exceptions to this generalization. In the case of the English diphthong [ei], it is often, though not always, replaced by the simple Hangul vowel $\langle\|\|\rangle$ as shown in (9a) below. Other cases follow the more typical diphthongal representation, < - as in $(9 b)$. 


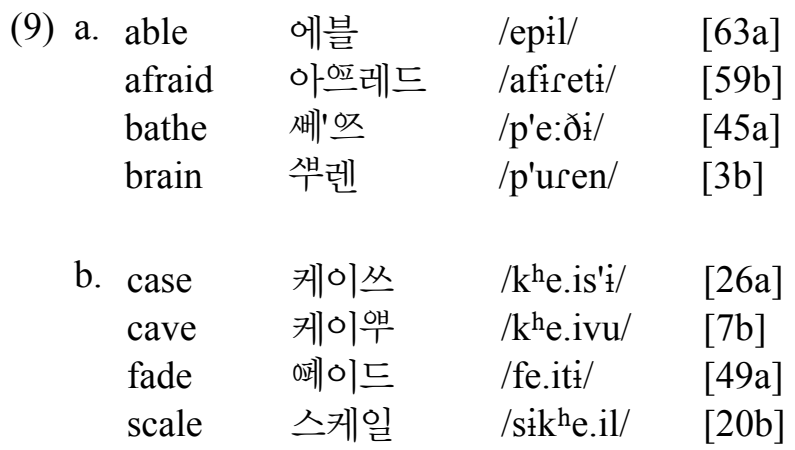

The difference between English [æ] and [ع], which does not exist in present-day Korean, or is at least rare, is indicated by JSY using the Hangul symbols $H$ and $-\|$, reflecting the earlier values of these symbols.

\begin{tabular}{|c|c|c|c|}
\hline (10) bad & 새드 & /p'ætí/ & [32b] \\
\hline sad & 쌔드 & /s'æti/ & [58b] \\
\hline shallow & 쇌노우 & /swelno.u/ & [51b] \\
\hline bell & 셀ㄹ & $/ \mathrm{p}^{\prime} \mathrm{el} /$ & [22b] \\
\hline leg & 을레그 & /ìlreki/ & {$[3 b]$} \\
\hline sell & 쎄르 & /s'el/ & {$[45 \mathrm{~b}]$} \\
\hline
\end{tabular}

Other English vowels are represented by additional symbols. For instance, the vowel found in words like bird, fur, etc., is represented as in (11) below:
(11) bird
서드
/p'stí/
[20a]
fur garment
어'싸'맨트'
/fo:ka':mænt ${ }^{\mathrm{h}} \mathbf{i} /$
[29a]
word
우워드
/u.otí/
[44a] 


\subsection{Additional Phonetic Symbols}

JSY employs additional diacritics in order to represent some of the phonetic modifications found in spoken English, including labialization, palatalization, and vowel length.

Labialization, found in a number of contexts in English, is indicated in JSY's system by the use of the vowel symbol $T / \mathrm{u} /$ added to a syllable, as in tree 투리 $/ \mathrm{t}^{\mathrm{h}} \mathrm{uri} /$ [11a], pretty 푸리티 $/ \mathrm{p}^{\mathrm{h}}$ $\mathrm{urit}^{\mathrm{h}} \mathrm{i} /$ [50a], brook 수룩크 / $\mathrm{p}^{\prime} \mathrm{urukk}^{\mathrm{h}} \mathrm{i} /$ [8a], child 촤일드 $/ \mathrm{t} \int{ }^{\mathrm{h}} \mathrm{wa} . i 1 \mathrm{ti} /$ [1a], plum 풀럼 $/ \mathrm{p}^{\mathrm{h}} \mathrm{ul}$ ○วm/ [13b]. This records a subtle distinction not usually noted by English native speakers.

The labiovelar approximant [w] is indicated by the same symbol, even in contexts where Korean would disallow the sequence, e.g., 우어크만 $/ \mathrm{u} . \mathrm{k}^{\mathrm{h}} \mathrm{iman} /$ workman [45a], 우울으 /u.ul.fi/ wolf [17b], 우옴 /u.om/ worm [20a]. This is particularly interesting because such sequences are not found in Korean, but JSY recognizes their importance in English and encodes them as sequences in his transcription system.

Similarly, the Korean symbol for [i], I, is used to mark palatalization of sounds, as in (12a), and the related $\pi / \mathrm{ju} / \mathrm{in}$ (12b). Combined with labialization we encounter cases such as $(12 \mathrm{c})$.
a. beauty
시유티
/p'ijuthi/
flute
을뉴트
/fïlnjuth $\mathrm{h}_{\mathrm{i}} /$
bridge
수릿지
/p'uritd3i/
b. fuel
으율/으유엘
/fi.jul//fi.juel/
$[10 \mathrm{~b}] /[45 \mathrm{~b}]$
influence
인흘뉴엔쓰
/infílnjuens'í $[47 \mathrm{~b}]$
luxuriance
을넉슈렌쓰
/iln $\supset k \int j u r e n s ' i /[54 b]$ 


\section{c. fish 으쉬 /fuifwi/ [20a] ship 쉽 $/ \int w i p / \quad[23 b]$ chin 췬 $/ \mathrm{t} \int \mathrm{win} / \quad[3 \mathrm{~b}]$}

A final area of modification in the English transcriptions involves the use of the single quotation mark, $/ 1 /$, to indicate vowel length. This is used, as mentioned above, to distinguish tense from lax vowels, as well as for indicating the extra length of diphthongs and the absence of final $/ \mathrm{r} /$.

Examples of long vowels indicated in the AP include the cases in (13a), while cases of diphthongs with a length mark include those in (13b). Cases of final $/ \mathrm{r} /$ marking are provided in (13c).

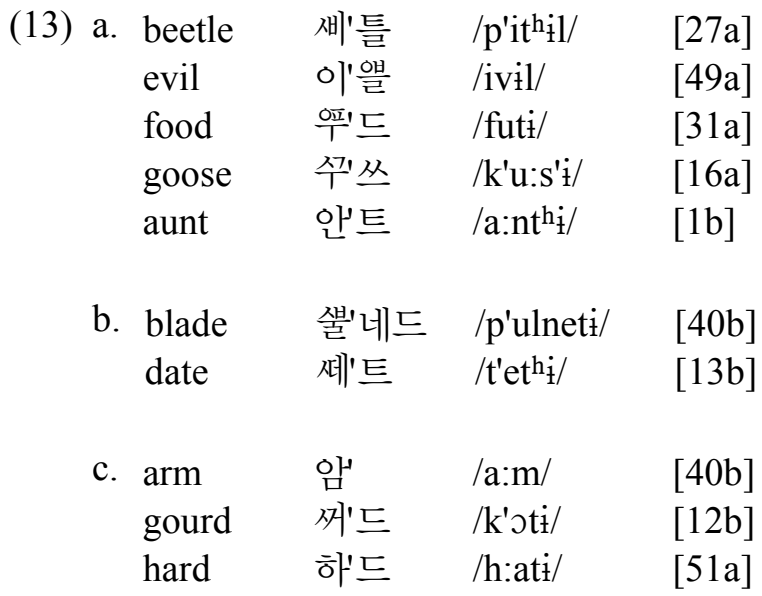

This concludes the examination of the various conventions introduced by JSY for representing English pronunciation. We now take a brief look at the possible sources of English pronunciation data in the AP. 


\section{Source of English Pronunciation}

The English pronunciation of the words in the AP suggests a British origin, although there is little lexical evidence for this. The strongest indicator of a British source is the non-rhotic nature of the pronunciation. It should be noted, however, that certain American varieties, especially in the late 19th / early 20th century were also non-rhotic and some continue to be.

The spelling of words such as neighbour, arbour, and saltpetre also suggests a British source, since these follow British spelling conventions rather than the American ones. Nevertheless, there are pairs of forms with alternate spellings, such as favor [58a] and favour [48a] or honor [32b] and honour [49a], which muddy the waters.

The transcription of words such as harem also provides evidence of a British pronunciation, specifically the quality of the first vowel, transcribed as 헤아렘 /he.arem/. For instance, Michaelis \& Jones (1913: 184), in their English Dictionary, transcribes harem as ['heərem] with a diphthong in the first syllable, suggesting that this is the usual British pronunciation of the word at the time. Kenyon \& Knott's (1953) Pronouncing Dictionary of American English of the early 20th century ("cultivated colloquial English of the United States") suggests a rather different pronunciation for the American form of the word, [ herəm].

One possible explanation for the variation in spelling and pronunciation may be that there was more than one scholar working on different sections of the AP, resulting in some inconsistency in the final product. This possibility will be discussed further in the following section. 


\section{Irregularities in the Ahak Pyeon}

Irregularities in the English entries of the AP stem from several sources. First of all, there are typographic errors presumably introduced by the printer, who was most likely not familiar with English orthography, perhaps not with English at all. This should not be surprising at a time when very little English was being used in Korea and none in traditional-style books of the sort of the AP. Examples of typographic errors of this sort include $<$ Dhid $>$ for child, <birb> for bird, < drizzy> for drizzly, etc. It is JSY's transcriptions that point to the error being committed by the printer in such cases, since the Hangul transcriptions of these words are accurate representations of the English words, i.e., 촤일 드 $/ \mathrm{t}^{\mathrm{h}} \mathrm{wa}$.ilti $/$, 서드 $/ \mathrm{p}^{\prime}$ 'tit $/$, 스리 쓸니 /t'iris'ilni/, respectively, in spite of the errors in English orthography.

The second type of error has more to do with JSY's (or perhaps Jeon Yong-gyu's) knowledge of English. Little is known about the source of their understanding of English pronunciation, but there are clear gaps, as well as clear insights in his transcriptions of English words. For instance, the English word doctor is transcribed as 쏙토 $/ \mathrm{t}^{\prime} \mathrm{ok} \mathrm{t}^{\mathrm{h}} \mathrm{O} /$ and scholar as 스콜라 $/ \mathrm{sik}^{\mathrm{h}} \mathrm{olra} / \mathrm{but}$, in fact, both words end in the same rhyme, typically represented as -1. Another example is anus, a medical term that JSY, as a physician, would have been familiar with, which is rendered as 아 뉴쓰 /anjus'íl, instead of the usual English pronunciation ['eInəs]. The transcription of this form is reminiscent of the French pronunciation of the word. It is possible that it is due to the pronunciation of other similar words such as annular ['anələr], which does contain a palatalized [n]. Another curious example is that for intestines, which is transcribed as 인테쓰티네쓰 /int ${ }^{\mathrm{h}} \mathrm{es}^{\prime} \mathrm{t}^{\mathrm{h}}{ }^{\mathrm{innes}} \mathrm{i} /$. The pronunciation of the final syllable is distinctly odd, as if it is over-pronounced.

One clear indication that JSY made use of information from 
dictionaries for at least some of the English data comes from the curious gloss found for the Chinese character 塐 [28a]. The English gloss for this is given as "Militar-banne-ry" for the presumably correct "Military banner." This was clearly not elicited from a native speaker nor would it be recalled from memory in this form. The only way that this could have arisen is from a written source where both words were hyphenated, perhaps to suit the narrow columns of a dictionary. Furthermore, this cannot be attributed to a typographic error from the printer, given the

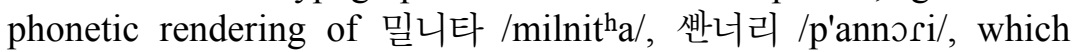
replicates the misrepresentation and even the word break, marked with a comma. This case demonstrates that dictionaries must have been used for at least some of the data included in the AP.

Over-reliance on English orthography is responsible for some of the errors in pronunciation, e.g., cupboard is transcribed as 컵푸소아드, $/ \mathrm{k}^{\mathrm{h}} \supset \mathrm{pp}^{\mathrm{h}} \mathrm{up}$ 'o.a.ti/ indicating pronunciation of both [p] and [b] when this did not occur in English at this time. Obviously, this is the result of a spelling pronunciation. A number of words, including beard, friend, learn, are also transcribed based on their spelling. These errors suggest that JSY may not have been very familiar with the English language even though his transcription system shows a great deal of sophistication.

A final source of error in the AP arises from inconsistency in transcription. As noted above, this may be due to the involvement of different individuals in the compilation of different sections of the AP. For instance, there are American/British spelling doublets such as favor [58a] / favour [48a] and honor [32b] / honour [49a] found in different places in the book. Furthermore, there are fluctuations in the systematic use of certain features such as the distinction between English $/ \theta /$ and $/ \delta /$, which is maintained in the initial part of the AP as $O[$ versus 0 , , but is lost in the latter part of the book, all forms being represented only by Oᄌ. Additionally, there is some inconsistency in the choice of vowel in certain words, such as book 스크 $/ \mathrm{p}^{\prime} \mathrm{kk}^{\mathrm{h}} \mathrm{i} /$ [1a] and 수크 $/ \mathrm{p}^{\prime} \mathrm{uk}^{\mathrm{h}} \mathrm{i} /$ [24b], 
swallow 스왈로우 /siwalro.u/ [17a] and 수월노우 /suw 1 lno.u/ [37a], etc. All of these factors suggest the involvement of more than one individual in the creation of the AP.

It should be noted that these errors, while obviously affecting the usability of the text, do not detract from the value of the system itself. Such errors could have been easily addressed in a revised version with input on pronunciation from native speakers, but circumstances prevented such corrections from rectifying these problems.

\section{Summary and Conclusions}

In this paper, we have established that JSY made several significant contributions to English education in Korea in the 1908 version of the AP. First of all, he included English words in the entries in the AP, allowing learners access to a previously inaccessible but increasingly important international language. This indicates his foresight and openness to progressive ideas in the field of education.

Secondly, he included substantial phonetic information on the pronunciation of each English word in the entries as discussed above. This required him to gain a thorough understanding, not only of English phonetics, but also of English pronunciation in order to make the best possible representations of each word. In order to accomplish this he must have conducted extensive research to collect the English data from native speakers, dictionaries, and whatever other sources were at his disposal.

We have also pointed out that JSY developed a system of transcription that allowed learners already familiar with the Hangul writing system to approximate a pronunciation of English. This system facilitated access to English, as well as Mandarin Chinese and Japanese, pronunciation for Korean learners by employing a 
familiar system, Hangul, with modifications to extend its use to English. This amply demonstrates JSY's deep understanding of the principles of the Hangul writing system as set out in the Hunmin Jeong-eum and related works. Not only did JSY's system make use of the existing Hangul symbols, both current and archaic, but he also made modifications consistent with the original system in order to represent sounds that had not been anticipated by the original developers of the Hunmin Jeong-eum.

This paper has discussed three important issues related to the early work of JSY: i) the adaptation of the Hangul alphabet as a phonetic system; ii) the potential of this system for the teaching of English, especially for the early development of phonemic awareness in the learner; and iii) insights into the early contact period awareness and pronunciation of English.

Certain questions remain to be answered, including where JSY got his English data and how he acquired his knowledge of phonetics. One may speculate on the possible sources of data, for instance Western colleagues at the Medical school or acquaintances from church, or an English phonetic dictionary, but the question remains open.

\section{References}

Choi, Y. 2006. <Ahakpyeon>, Junggugeo eumunchekgye yeongu [Studies of Chinese phonology system]. MA Thesis. Hankuk University of Foreign Studies.

Han, S-U. 2007. Gaehwagi sinmunui waelae-eo pyogie daehan eumunlonjeok yeongu [A phonological study on loanwords in newspapers in the enlightenment periods (1896-1910)]. Eomunhak [Language and Literature] 95, 281-309. . 2009. Ahakpyeoneul tonghae bon geundae dongasia eoneogyolyu [The state of language interchange in Modern 
East Asia through Ahakpyeon]. Hankukhak Bunseok [Korean studies analysis] 21, 267-301.

. 2010. Gaehwagi walae-eo pyogi eumunlon [A phonological study on loanwords in enlightenment periods (1896-1910)]. Urimalgeul: The Korean Language and Literature 49, 63-86. Jeong, Y-Y. 1805. Myeongmul Sohak. Available at URL $<$ http://www.hangeulmuseum.org/sub/information/bookData/tot al_List.jsp?d_code $=00452 \& g$ _class $=>$.

Ji, S-Y. . 1908. Ahak Pyeon. Available at URL <http://www.hangeul museum.org/sub/information/bookData/detail.jsp?d_code $=0001$ 2\&kind $=$ G\&g_class $=04>$.

. 1910. Ahak Pyeon. Available at URL <http://www.dibrary.n et/search/dibrary/SearchDetail.nl?category_code $=$ ct\&service $=K$ OLIS\&vdkvgwkey $=1162901 \&$ colltype $=$ DAN_OLD\&place_cod

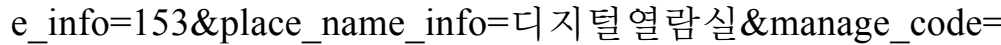
MA\&shape_code $=\bar{B} \&$ refLoc $=$ portal $\&$ category $=$ storage $\& \operatorname{srchF} 1$ $\mathrm{ag}=\mathrm{Y} \& \mathrm{~h} \_\mathrm{kwd}=\mid \&$ lic_yn $=\mathrm{N} \& \mathrm{mat} \_$code $=\mathrm{RB} \&$ guCode $3=$ null $\# \mathrm{du}$ mmy>.

Kenyon, J. \& T. Knott. 1953. A Pronouncing Dictionary of American English. Springfield, MA: Merriam-Webster.

Kyōto Daigaku Bungakubu Kokugogaku Kokubungaku Kenkyūshitsu. (comp. \& ed.) 1970. Jigakuhen. Nichigo Ruikai. Kango Shoho. Kyōto: Kyōto Daigaku Kokubun Gakkai.

Lee, K-M. \& S. Ramsey. 2011. A History of the Korean Language. Cambridge: Cambridge University Press.

Lee, K. 2009. Jeongmongyueo, Ahakpyeon, Cheonjamun-ui bunpojeok teukseong [A distributive property on Jeongmongyueo, Ahakpyeon, Cheonjamun]. Journal of Linguistic Science 48, 101-123.

MacKenzie, R. 1895. T'aesŏ sinsa [Korean translation of The 19th Century: A History]. Seoul: Hakbup'yŏnjipguk.

Michaelis, H. \& D. Jones. 1913. A Phonetic Dictionary of the English Language. Hanover-Berlin: Carl Meyer \& Gustav Prior. 
Proctor, M., C. Shadle \& K. Iskarous. 2006. An MRI Study of Vocalic Context Effects and Lip Rounding in the Production of English Sibilants. Proceedings of the 11th Australian International Conference on Speech Science \& Technology 307-312. University of Auckland.

Shin, Y. 2000. Gaehwagi gukeo pyogibeop yeongu [A study on Korean writing system in the civilization period]. Ph.D. Dissertation. Cheongju University.

Seong, H. 2002. Ahakpyeone boi-neun ilboneowa ilbonhanja-eo-ui ogi pyogie daehayeo [Wrong notation of sounds of Japanese and Chinese characters in Japanese shown in Ahakpyeon revised]. The Association of North-East Asian Cultures 2, 45-65.

Stonham, J. \& E-S. Kim. 2010. The Phonetic Value of Middle Korean $\triangle$. In R. Fouser (ed.), Contemporary Korean Linguistics: International Perspectives 348-378. Seoul: Thaehaksa. 